\title{
Harmonic Mitigation for Non-linear Load Using TSH Active Power Filter with PID Controller
}

\author{
Garima Sinha, Pankaj Kumar Goswami, Sudhir kr. Sharma \\ Department of Electronics and communication Engineering, Jaipur National University, India
}

\begin{tabular}{l} 
Article Info \\
\hline Article history: \\
Received Feb 20, 2018 \\
Revised Apr 5, 2018 \\
Accepted Apr 24, 2018 \\
\hline
\end{tabular}

\section{Keyword:}

Active power filter

MATLAB/simulation

PID controller

Power factor

Power quality

THD

\begin{abstract}
Electronic equipments, widely used in present living era, required to have improved power quality. When such type of equipments are connected to electric supply distribution system, they introduce non sinusoidal effect in the line current because of their non-linear relationship in voltage and current. Moreover, harmonics in the line current are also produced. With constantly growing imploration of such type of nonlinear equipments at a large scale, harmonic distortions in line current have become a significant crunch. This required some methods involving the reduction of harmonics in the line current as well as power factor improvement/correction. The primary goal of this proposed work is to reduce the harmonics produced in line current and to improve power quality of non-linear load by designing a converter with parallel processing scheme, named TSH active power filter (transformer less shunt active power filter) with PID controller. Here a separate dc source is employed to supply the shunt connected converter, a voltage source inverter, to remove the requirement of bulky transformer at supply end. This paper depicted the process of reduction of total harmonic distortion (THD), generated due to nonlinear characteristics of load and power factor improvement by shunt compensation. The proposed designs are modeled and simukated using Matlab simulation software.
\end{abstract}

Copyright $\odot 2018$ Institute of Advanced Engineering and Science. All rights reserved.

\section{Corresponding Author:}

Garima Sinha,

Department of Electronics and Communication Engineering,

Jaipur National University,

Jagat-Pura, Jaipur, India.

Email: grmsinha@gmail.com

\section{INTRODUCTION}

As in recent years, power quality has been most important research topic because of widespread use of non-linear loads using electronic equipment's such as rectifiers, switched mode power supply (SMPS), Laptop, incandescent lighting and motor drive applications etc [1]. These power-electronic-based loads offer highly nonlinear characteristics. They are also responsible for lower efficiency and interference of distribution system with the nearby communication networks. To improve the efficiency, capacitors are employed which also leads to the improvement of the power factor of the mains. To reduce the interference with the communication network due to harmonics in the current flowing in the distribution system, passive L-C filters are used. But they have the limitations of fixed compensation, large size, and that they can create new system resonance as they are tuned for specific frequency thus have limited operating frequency range.

To overcome these problems and to get better results active power filters (APFs) have been developed. The researchers in [2] use Transformer less series active power filter for non-linear load, to reduce harmonics in load current to $14 \%$ and in source current to $2.1 \%$. In [3] researchers observe that when shunt active filter is used along with PV module and fuzzy controller for harmonic reduction of non-linear load, the harmonics of the phase A is mitigated from $19.84 \%$ to $1.53 \%$ and the THD for other two Phases B and $\mathrm{C}$ is reduced from $20.98 \%$ to $1.55 \%$ and $19.82 \%$ to $1.50 \%$. In [4] the response of fuzzy controller and PI 
controller are compared when used for active power filteration with UPQC for non-linear loads. In UPQC both series and shunt converters are used for harmonic compensation. The work in [5] also give a successsfull effort in reduction of THD in line current to $14.21 \%$ for non-linear loads by using UPQC with fuzzy logic controller.In [6] pattern search method is used to reduce harmonics for 13, 15 and 17 level inverters for R,R-L and motor load but the researchers did not give the exact numeric value of reduced THD.Thus the voltage-source-inverter (VSI)-based shunt active power filter has been used in recent years and recognized as a viable solution. These Active filters comprise of semiconductors switching devices like IGBT, MOSFET, GTO's etc. The turn-on and turn-off time of these switching devices is decided by the gate pulse applied to it, which is controlled by an appropriate controller. Thus there is an active contribution of shunt connected auxiliary converter infiltration of harmonic components or in the reduction of THD from line current, hence they are called as ShAPF (shunt active power filter).

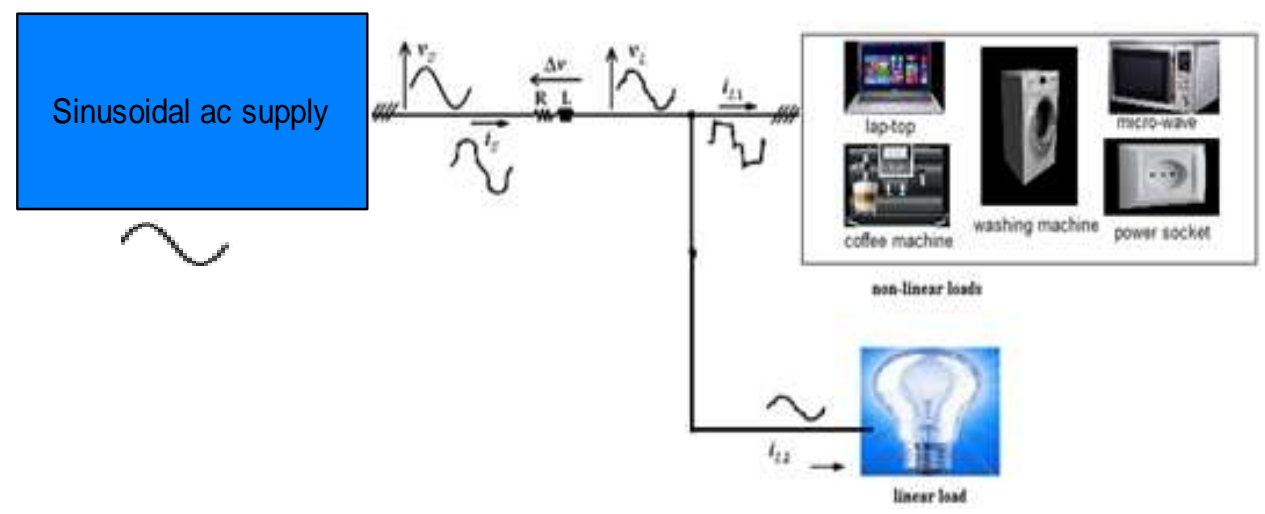

Figure 1. Sinusoidal supply feeding linear and non-linear loads

\section{NEED OF HARMONIC REDUCTION}

In the present scenario, the use of semiconductor devices is increasing day by day, as the complex control circuitry can be reduced to a compact circuit with a remarkable reduction in weight and size. For most of the electronic equipments that are used in our daily life, such as personal computers, Laptop, Television, Microwave, Mobile phones etc. (as shown in Figure 1), there is a growing demand of power electronic converters. For the proper working of electronic devices used in residential, industrial and commercial applications power conditioning such as rectification is needed [7]. But as we know that the semiconductor devices used in rectifiers/converters and other electronic equipments are non-linear devices having non-linear characteristics, on connection of these electronic equipments to the main supply, a nonsinusoidal current with harmonic distortions is produced, which affect the whole distribution network.

With the steadily increasing requirement of such kinds of equipment at a fast rate, the problem due to harmonic distortions in line current has become quite significant [8]. A lot of international standards have been introduced to pose limitations on the line current harmonics of equipments which are connected to an electrical distribution system. This requires for various techniques to reduce the harmonic distortions in line current which can also be known as Power Factor Correction [9].

\section{PROPOSED CIRCUIT MODEL FOR ACTIVE PFC}

Figure 2 presents the circuit diagram of proposed methodology, here our main purpose is to reduce the harmonics in line current, make it sinusoidal having almost zero phase difference with supply voltage [10], and also to improve load power factor, for this we connect an appropriate converter (which is basically a voltage source inverter) in shunt with the main converter (diode bridge rectifier) acting as a non-linear load. This shunt connected converter is a controlled rectifier having a semiconductor switching device (here IGBT) whose gate pulse is applied in such a manner that it is turned-on for harmonic component and turned-off for main or fundamental component of line current which results in sinusoidal line current. 


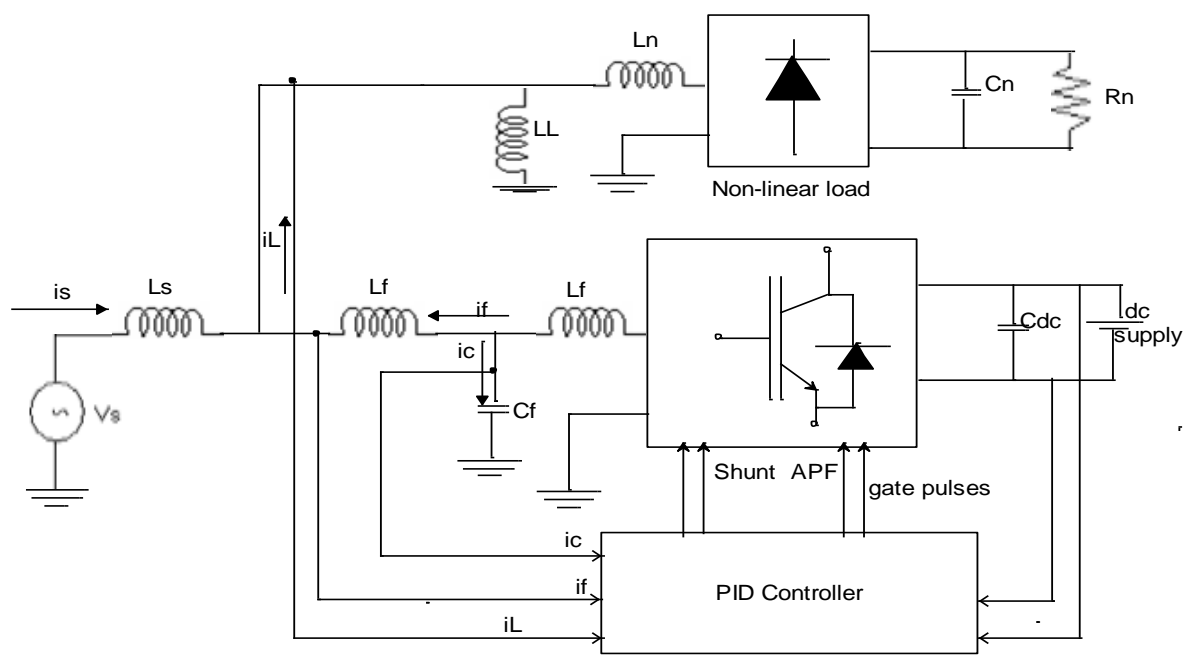

Figure 2. Block diagram of proposed model

Thus the parallel combination of uncontrolled bridge rectifier (non-linear load) and auxiliary converter(voltage source inverter) acts as a resistive load hence provides a sinusoidal line current and load power factor close to unity. In order to generate the gate pulse as per the requirement a control circuitry is provided to control the dc out-put voltage of non-linear load. A separate dc power supply is provided to auxiliary converter connected in shunt with the non-linear load; this eliminates the requirement of transformer at supply end [11]. Table 1 shows the values of configuration parameters that we consider as reference parameters for proposed circuit model.

Table1. Configuration Parameters

\begin{tabular}{lc}
\hline \multicolumn{1}{c}{ Description } & Parameters \\
\hline Supply voltage(peak value),frequency & $155 \mathrm{~V}, 50 \mathrm{~Hz}$ \\
Source resistance, inductance & $\mathrm{R}_{\mathrm{s}}=0.1 \mathrm{ohm}, \mathrm{L}_{\mathrm{s}}=0.5 \mathrm{mH}$ \\
Filter resistance, inductance & $\mathrm{R}_{\mathrm{F}}=1 \mathrm{ohm}, \mathrm{L}_{\mathrm{F}}=1 \mathrm{mH}$ \\
Non-linear-load, resistance inductance, capacitance & $\mathrm{R}_{\mathrm{N}}=95 \mathrm{ohm}, \mathrm{L}_{\mathrm{N}}=1 \mathrm{mH}, \mathrm{C}_{\mathrm{N}}=470 \mu \mathrm{F}$ \\
DC bus capacitor, Voltage & $\mathrm{C}_{\mathrm{dc}}=1 \mathrm{mF}, \mathrm{V}_{\mathrm{dc}}=300 \mathrm{~V}$ \\
PID Controller coefficient & $\mathrm{K}_{\mathrm{P}}=0.7, \mathrm{~K}_{\mathrm{D}}=.01, \mathrm{~K}_{\mathrm{I}}=23$ \\
Linear-load resitance,inductance & $\mathrm{R}_{\mathrm{L}}=3 \mathrm{ohm}, \mathrm{L}_{\mathrm{L}}=70 \mathrm{mH}$ \\
\hline
\end{tabular}

\section{PRINCIPLE OF CONTROL STRATEGY}

Here we have the overall mathematical analysis, describing the various current equations. The instantaneous equation of source current and source voltage is:

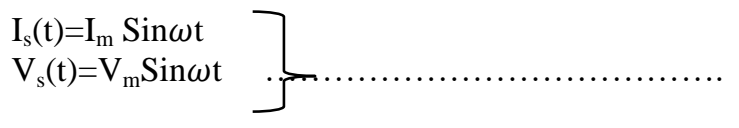

As this single phase supply is connected to non-linear load (here diode bridge rectifier with R-L load), anon-sinusoidal line current is drawn from the supply with significant harmonic distortions, now supply current $I_{s}(t)$ becomes $I_{s}^{\prime}(t)$, as explained by eqn $2-4$

$$
\mathrm{I}_{\mathrm{s}}^{\prime}(\mathrm{t})=\sum_{n=1}^{\infty} \mathrm{I}_{\mathrm{n}} \operatorname{Sin}\left(\mathrm{n} \omega \mathrm{t}+\varphi_{\mathrm{n}}\right)
$$

$\mathrm{I}_{\mathrm{s}}^{\prime}(\mathrm{t})=\mathrm{I}_{1} \operatorname{Sin}\left(\omega \mathrm{t}+\varphi_{1}\right)+\underbrace{\infty}_{n=2} \mathrm{I}_{\mathrm{n}} \operatorname{Sin}\left(\mathrm{n} \omega \mathrm{t}+\varphi_{\mathrm{n}}\right)$

Fundamental component Harmonic component

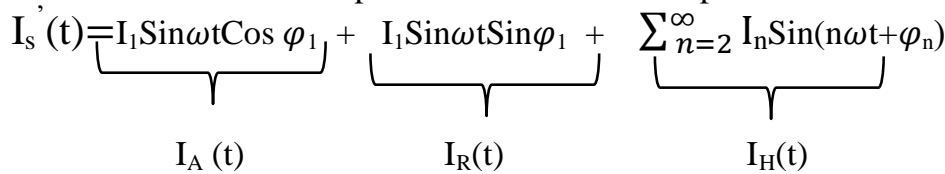


Hence now the supply current $\mathrm{I}_{\mathrm{S}}{ }^{\prime}(\mathrm{t})$ is phasor sum of active component $\left(\mathrm{I}_{\mathrm{A}}\right)$, reactive component $\left(\mathrm{I}_{\mathrm{R}}\right)$, and harmonic component $\left(I_{H}\right)$ of line current. Here our control strategy is to compensate $I_{R}$ and $I_{H}$ components from the line current by reduction of THD (total harmonic distortions).

The power drawn by the non-linear load can be obtained by multiplying the source current given by (4) $\left[I_{s}^{\prime}(t)\right]$ to source voltage given by (1) [12].

$$
\begin{aligned}
& \mathrm{P}_{\mathrm{L}}(\mathrm{t})=\mathrm{I}_{\mathrm{S}}^{\prime}(\mathrm{t}) * \mathrm{~V}_{\mathrm{s}}(\mathrm{t}) \\
= & \mathrm{V}_{\mathrm{m}} \operatorname{Sin} \omega \mathrm{t}\left[\mathrm{I}_{1} \operatorname{Sin} \omega \mathrm{t} \operatorname{Cos} \varphi_{1}+\mathrm{I}_{1} \operatorname{Sin} \omega \mathrm{t} \operatorname{Sin} \varphi_{1}+\sum_{n=2}^{\infty} \mathrm{I}_{\mathrm{n}} \operatorname{Sin}\left(\mathrm{n} \omega \mathrm{t}+\varphi_{\mathrm{n}}\right)\right. \\
= & \mathrm{V}_{\mathrm{m}} \operatorname{Sin} \omega \mathrm{t} \mathrm{I}_{1} \operatorname{Sin} \omega \mathrm{t} \operatorname{Cos} \varphi_{1}+\mathrm{V}_{\mathrm{m}} \operatorname{Sin} \omega \mathrm{t} \mathrm{I}_{1} \operatorname{Sin} \omega \mathrm{t} \operatorname{Sin} \varphi_{1}+\mathrm{V}_{\mathrm{m}} \operatorname{Sin} \omega \mathrm{t} \sum_{n=2}^{\infty} \mathrm{I}_{\mathrm{n}} \operatorname{Sin}\left(\mathrm{n} \omega \mathrm{t}+\varphi_{\mathrm{n}}\right. \\
= & \mathrm{P}_{\mathrm{F}}(\mathrm{t})+\mathrm{P}_{\mathrm{R}}(\mathrm{t})+\mathrm{P}_{\mathrm{H}}(\mathrm{t})
\end{aligned}
$$

Thus the total power drawn is phasor sum of fundamental power or active power $\mathrm{P}_{\mathrm{F}}(\mathrm{t})$, reactive power $\mathrm{P}_{\mathrm{R}}(\mathrm{t})$ and harmonic power $\mathrm{P}_{\mathrm{H}}(\mathrm{t})$. If the gate pulse of IGBT, employed in VSI is applied in such a manner so that the harmonic power and reactive power is provided by the APF then only active power is drawn by the source, which is multiplication of $\mathrm{I}_{\mathrm{A}}(\mathrm{t})$ ( given by eq ${ }^{\mathrm{n}} 4$ ) and $\mathrm{V}_{\mathrm{s}}(\mathrm{t})$.

$$
\mathrm{P}_{\mathrm{F}}(\mathrm{t})=\mathrm{V}_{\mathrm{s}}(\mathrm{t}) * \mathrm{I}_{\mathrm{A}}(\mathrm{t})
$$

Where $I_{A}(t)$ is the desired value of current $I_{S}$ " drawn by the source so that the ac source is responsible only for active power $\mathrm{P}_{\mathrm{F}}(\mathrm{t})$

$$
\begin{aligned}
& \mathrm{P}_{\mathrm{F}}(\mathrm{t})=\mathrm{V}_{\mathrm{m}} \operatorname{Sin} \omega \mathrm{t} * \mathrm{I}_{1} \operatorname{Sin} \omega \mathrm{t} \operatorname{Cos} \varphi_{1}[17]=\mathrm{V}_{\mathrm{s}}(\mathrm{t}) * \mathrm{I}_{\mathrm{A}}(\mathrm{t}) \\
& \mathrm{I}_{\mathrm{s}}^{\prime \prime}(\mathrm{t})=\mathrm{P}_{\mathrm{F}}(\mathrm{t}) / \mathrm{V}_{\mathrm{s}}(\mathrm{t}) \\
& \mathrm{I}_{\mathrm{s}}^{\prime \prime}(\mathrm{t})=\mathrm{V}_{\mathrm{m}} \mathrm{I}_{1} \operatorname{Sin}^{2} \omega \mathrm{t} \operatorname{Cos} \varphi_{1} / \mathrm{V}_{\mathrm{m}} \operatorname{Sin} \omega \mathrm{t} \\
& \mathrm{I}_{\mathrm{s}}^{\prime \prime}(\mathrm{t})=\mathrm{I}_{1} \operatorname{Cos} \varphi_{1} \operatorname{Sin} \omega \mathrm{t} \\
& \mathrm{I}_{\mathrm{s}}^{\prime \prime}(\mathrm{t})=\mathrm{I}_{\max } \operatorname{Sin} \omega \mathrm{t}
\end{aligned}
$$

This is the sinusoidal current in phase with supply voltage. As it is clear from the block diagram (Figure 2) that two converters are connected in parallel, the out-put DC voltage of auxiliary converter is regulated with the help of controller in order to estimate the maximum value of supply current $\mathrm{I}_{\max }$ and according to this value of reference current the gate pulse for IGBT's are generated. As a result the current injected by VSI is equal and opposite in phase with the harmonic component $\left(\mathrm{I}_{H}\right)$ and reactive component $\left(\mathrm{I}_{R}\right)$ of the line current.

$$
I_{F}(t)=-I_{R}-I_{H}
$$

Let us apply Kirchhoff's current law at the junction point of common coupling PCC [13]

$$
I_{L}(t)=I_{s}(t)+I_{F}(t)
$$

The load current $I_{L}(t)$ is phasor sum of source current $I_{S}(t)$ and filter current $I_{F}(t)$. Here the out-put current of VSI is called as filter current as it is working as an Active Power Filter in combination with passive filter component $\mathrm{L}_{\mathrm{f}}$ and $\mathrm{C}_{\mathrm{f}}$ and a PID controller.

$$
I_{s}(t)=I_{L}(t)-I_{F}(t)
$$

From (4), (15) \& (17), the the load current $I_{L}=I_{\max } \operatorname{Sin} \omega t$ which in-tern is equal to the reference value of supply current. 


\section{RESULT AND DISCUSSION}

Here the analysis of power quality is being done in two cases of non-linear load applications.In case (i) the simulation results are being depicted when the sinusoidal ac supply is connected to a non-linear load and in case (ii) the simulation results of same parameters are shown when the same circuit of case (i) is fed with TSh active power filter.

\subsection{Case (1) analysis of power quality for non-linear load application}

When a sinusoidal supply is connected to a non-linear load, the line current becomes distorted, having THD 78.80\%. Figure 3(a)-3(d) shows the simulated results of the input voltage, input current,THD of supply current,and FFT analysis of THD in line current respectively.

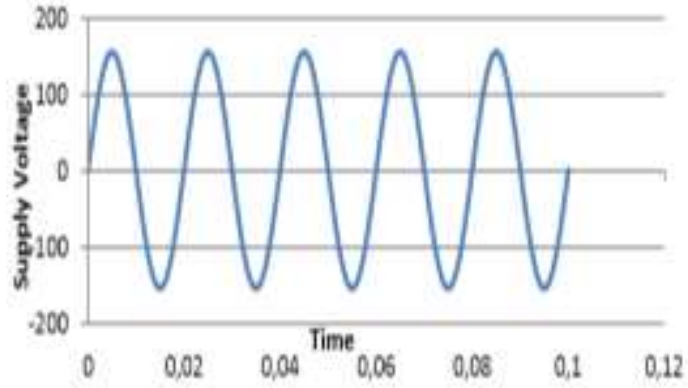

(a)

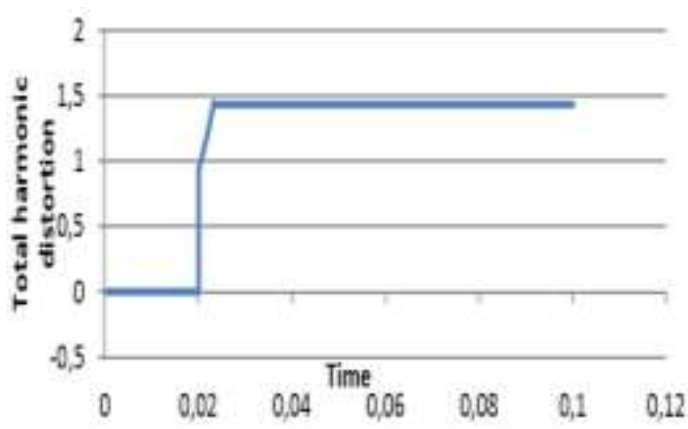

(c)

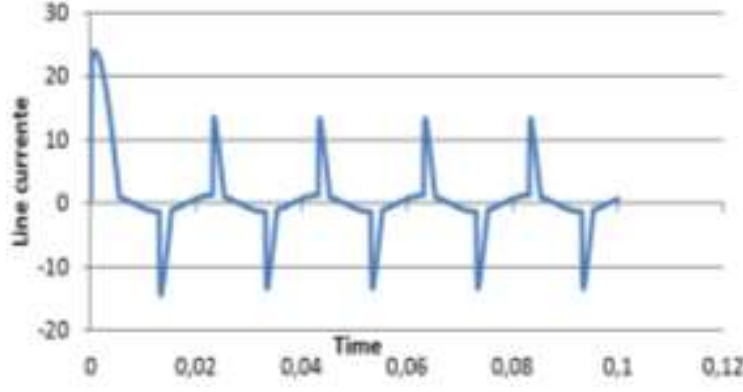

(b)

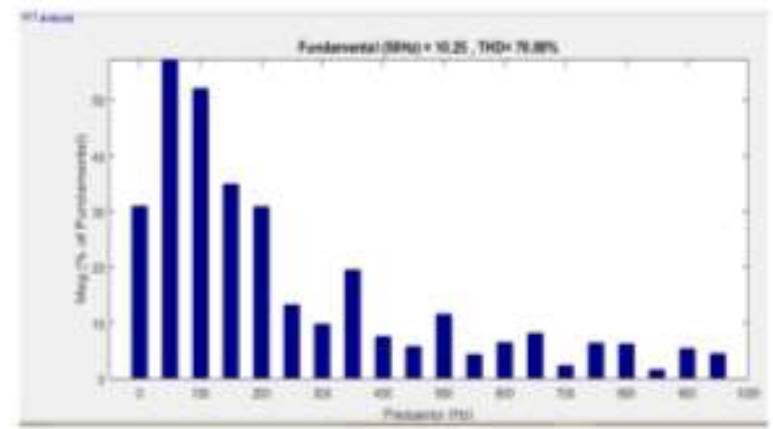

(d)

Figure 3. (a) Source voltage, (b) Line current, (c) THD, (d) FFT analysis of THD

\subsection{Case (2) analysis of power quality for nonlinear load with Tsh active power filter}

Now the control circuitry is designed, where a semiconductor switching device (here IGBT) is used in auxiliary converter, which is connected in parallel with the non-linear load.This auxiliary converter must be responsible for all harmonic components of line current so that the current passing to the load must have fewer harmonics [14]. The turn on and turn off time of IGBT must be such that it will be on for harmonic currents and off for main components of current, so the gate pulse of the IGBT must be controlled accordingly.To control the gate pulse of IGBT a PID controller is being used and then the simulation results are obtained.

By reviewing the work of other recherchers in introduction section, it is observed that in most of the work there is a need of bulky transformer between the supply-end and shunt converter which causes various losses and thus reduce system efficiency. The proposed methodology has major advantage of elimination of the need of transformer by providing a separate dc source to shunt converter. Thus the harmonics in line current are reduced to the permissible limit of IEEE standard 519, with out heavy losses. Figure 4(a)-4(d) shows the simulated results of the input voltage, input current, THD of supply current, and FFT Analysis of THD in line current respectively. Table 2 shows the value of \% THD and power factor in line current, before compensation and after compensation. 


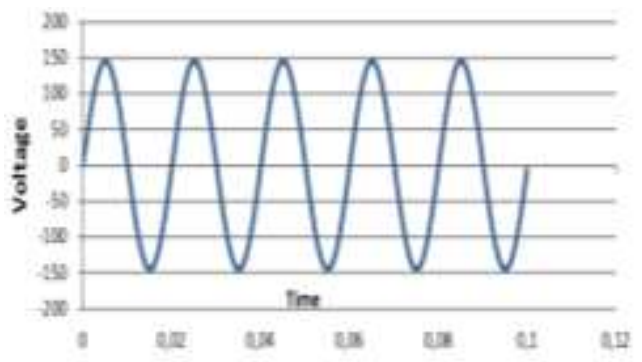

(a)

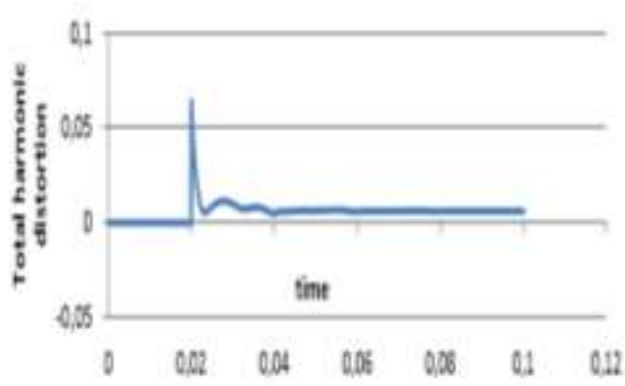

(c)

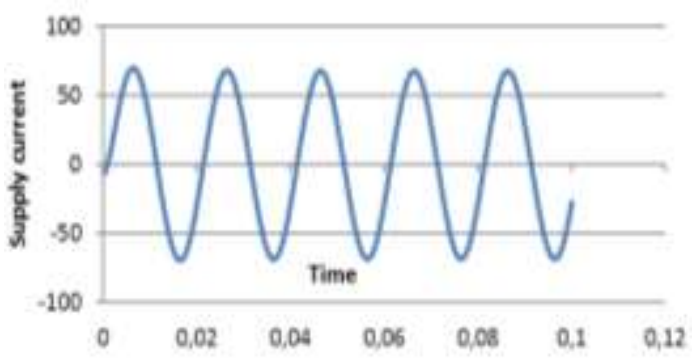

(b)

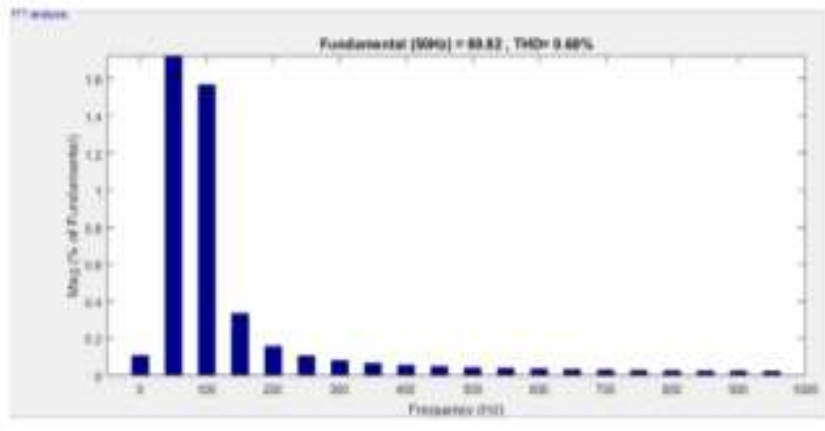

(d)

Figure 4. (a) Source voltage, (b) Source current, (c) THD, (d) FFT analysis of THD

Table 2. Results After Simulation

\begin{tabular}{ccc}
\hline Power Quality issues & Non-linear load & Non-linear load with TSHAPF \\
\hline Line Current & Distorted(Non sinusoidal) & Sinusoidal \\
$\%$ THD in line current & $78.8 \%$ & $0.61 \%$ \\
Power Factor & 0.2824 & 0.996 \\
\hline
\end{tabular}

\section{CONCLUSION}

The results shown in the favor of simultaneous improvement of overall power quality along with significant reduction in harmonics introduced, on non-linear load, in the line current. Modeling is done at initial level for depiction of Simulation of basic rectification process without any power factor correction. The variation in nature of line current is observed with respect to input voltage. A Power quality improvement circuit, consisting, an active power filter with PID controller is proposed, a separate dc source is used to supply the shunt connected converter i.e. voltage source inverter in order to eliminate the requirement of bulky transformer on supply side. The proposed work gives a very significant reduction in THD from $78.8 \%$ for non-linear load to $0.61 \%$ for non-linear load with TSH active power filter, also it is observed that the distorted line current becomes sinusoidal one.The simulation results of proposed model gives a very promising effect over the distortion introduced in harmonics as well as a significant improvement in total load power factor.

\section{REFERENCES}

[1] K. Nikum, R. Saxena and A. Wagh, "Effect on power quality by large penetration of household non linear load," 2016 IEEE 1st International Conference on Power Electronics, Intelligent Control and Energy Systems (ICPEICES), Delhi, 2016, pp. 1-5.

[2] A. Javadi, A. Hamadi, A. Ndtoungou and K. Al-Haddad, "Power Quality Enhancement of Smart Households Using a Multilevel-THSeAF With a PR Controller," in IEEE Transactions on Smart Grid, vol. 8, no. 1, pp. 465-474, Jan. 2017.

[3] R. Balamurugan, R. Nithya, "FC/PV Fed SAF with Fuzzy Logic Control for Power QualityEnhancement," International Journal of Power Electronics and Drive System, vol. 5, no. 4, pp. 470-476, April 201. 
[4] K.Ramalingeswara Rao, K.S. Srikanth, "Improvement of Power Quality using Fuzzy Logic Controller in Grid Connected Photovoltaic Cell using UPQC," International Journal of Power Electronics and Drive System, vol. 5, no. 1, pp. 101-111, July 2014.

[5] C. Prakash, N. Suparna, "Design and Simulation of Phase-Locked Loop Controller Based Unified Power Quality Conditioner Using Nonlinear Loads," International Journal of Power Electronics and Drive System, vol. 2, no. 4, pp. 417-423, December 2012.

[6] Suresh N.1, R. Samuel Rajesh Babu, "Reduction of Total Harmonic Distortion in Cascaded H-Bridge Inverter by Pattern Search Technique," International Journal of Electrical and Computer Engineering, vol. 7, no. 6, pp. 32923298, December 2017,

[7] L. Asiminoaei, E. Aeloiza, P. N. Enjeti and F. Blaabjerg, "Shunt Active-Power-Filter Topology Based on Parallel Interleaved Inverters," in IEEE Transactions on Industrial Electronics, vol. 55, no. 3, pp. 1175-1189, March 2008.

[8] A. Teke, L. Saribulut and M. Tumay, "A Novel Reference Signal Generation Method for Power-Quality Improvement of Unified Power-Quality Conditioner," in IEEE Transactions on Power Delivery, vol. 26, no. 4, pp. 2205-2214, Oct. 2011.

[9] J. He, Y. W. Li, F. Blaabjerg and X. Wang, "Active Harmonic Filtering Using Current-Controlled, Grid-Connected DG Units With Closed-Loop Power Control," in IEEE Transactions on Power Electronics, vol. 29, no. 2, pp. 642653, Feb. 2014.

[10] Zeng Zheng, Yang Jiaqiang and Yu Nianchang, "Research on PI and repetitive control strategy for Shunt Active Power Filter with LCL-filter," Proceedings of The 7th International Power Electronics and Motion Control Conference, Harbin, 2012, pp. 2833-2837.

[11] J. P. Bonaldo, H. K. Morales Paredes and J. A. Pomilio, "Control of Single-Phase Power Converters Connected to Low-Voltage Distorted Power Systems With Variable Compensation Objectives," in IEEE Transactions on Power Electronics, vol. 31, no. 3, pp. 2039-2052, March 2016.

[12] Karuppanan P., Kamalakanta Mahapatra, "PI, PID and Fuzzy Logic Controlled Cascaded Voltage Source Inverter based Active Filter for Power Line Conditioners," Wseas Transactions On Power Systems, vol. 6, no. 4, pp. 100109, October 2011.

[13] D. Phan, C. Nguyen and H. Lee, "A single-phase unified power quality conditioner with an enhanced repetitive controller," 2016 IEEE Energy Conversion Congress and Exposition (ECCE), Milwaukee, WI, 2016, pp. 1-6.

[14] B. Singh and J. Solanki, "An Implementation of an Adaptive Control Algorithm for a Three-Phase Shunt Active Filter," in IEEE Transactions on Industrial Electronics, vol. 56, no. 8, pp. 2811-2820, Aug. 2009.

\section{BIOGRAPHIES OF AUTHORS}

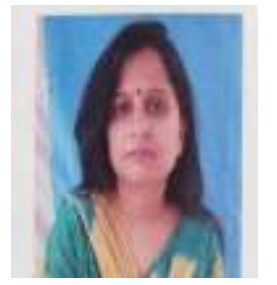

Ms.Garima Sinha has completed B.Tech. from U.P. Technical university in 2005. She obtained M.Tech. Degree in the field of control and instrumentation from RGPV University Bhopal in 2012. Presently, She is working as Research Scholar in Jaipur National University, Jaipur and doing research in power electronics. Her areas of interest are power electronics and control engineering.

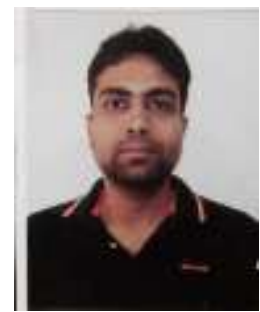

Mr. Pankaj Kumar Goswami completed B.Tech. from U.P.Technical university in 2005 . He obtained M.Tech. Degree in the field of Digital Communication from RGPV University Bhopal in 2012. Presently, he is working as Research Scholar in Jaipur National University, Jaipur and doing research in major areas of Electronic devices. His areas of interest are power electronics, antennas, and Embedded Systems.

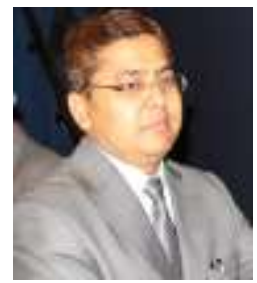

r. Sudhir Kumar Sharma is Joint Director \& Head (ECE), School of Engineering and Technology, Jaipur National University, Jaipur, Rajasthan, India. Professor Sharma received his Ph.D. in Electronics from Delhi University in 2000. Professor Sharma has an extensive teaching experience of 21 years. He has taught various engineering courses at graduate as well as at post-graduate level in India and Overseas.He has authored and coauthored over 110 National and International publications along with one book in Opto-Electronics titled "Introduction to Opto-Electronics and Optical-Communication", Printice Hall, Malaysia. He has also served on the editorial board of six international journals. 